\title{
Hereditary Angioedema with Recurrent Abdominal Pain in a Patient with a Novel Mutation
}

\author{
Hiromasa Yakushiji ${ }^{1}$, Arito Kaji ${ }^{1}$, Keitarou Suzuki ${ }^{1}$, Motohiro Yamada ${ }^{1}$, \\ Takahiko Horiuchi ${ }^{2}$ and Masahiro Sinozaki ${ }^{1}$
}

\begin{abstract}
We describe a patient with hereditary angioedema type I. The patient had experienced recurrent abdominal pain around the time of her menstrual period for 13 years. A laboratory examination showed reduced functional and antigenic levels of $\mathrm{C} 4$ and $\mathrm{C} 1$ inhibitor (C1-INH). To establish a diagnosis, we carried out a DNA analysis of the patient's $\mathrm{C} 1-\mathrm{INH}$ gene. We determined that the patient was heterozygous for a single base pair transposition of $\mathrm{T}$ to $\mathrm{C}$ at nucleotide 4429 in exon 4, which had not been reported in the literature. As the patient had no family history of hereditary diseases, it was considered to be a de novo mutation.
\end{abstract}

Key words: hereditary angioedema, abdominal pain, $\mathrm{C} 1$ inhibitor, $\mathrm{C} 1$ inhibitor gene, single base pair mutation

(Intern Med 55: 2885-2887, 2016)

(DOI: 10.2169/internalmedicine.55.6951)

\section{Introduction}

Hereditary angioedema (HAE) is an autosomal dominant disease characterized by recurrent episodes of potentially life-threatening angioedema (1). The clinical features of the disease include recurrent nonpruritic edema of skin and submucosal tissues associated with pain syndromes, nausea, vomiting, diarrhea, and life-threatening airway swellings (2). The fundamental abnormality in patients with HAE is a mutation of the $\mathrm{C} 1$ inhibitor (C1-INH) gene, which results in the decreased synthesis of functional C1-INH antigenic protein. Two forms of HAE have been described: in type I HAE patients have low C1-INH antigenic protein and functional activity (85\% of cases), while patients with type II HAE have normal or elevated protein but low C1-INH function (15\% of cases); in patients with a normal C1-INH gene, HAE is often referred to as type III HAE. Over 200 mutations have been reported in unrelated patients $(3,4)$. While HAE is known to be inherited in an autosomal dominant form, $25 \%$ of cases develop as a result of a de novo mutation (5).

We report a case of type I HAE with a newly recognized de novo mutation of the C1-INH gene.

\section{Case Report}

A 38-year-old woman presented to our emergency department with abdominal pain and nausea that had persisted for three hours. The patient had experienced recurrent episodes of skin edema, sometimes followed by vomiting with abdominal pain, around her menstrual period for 13 years. She had no family history of hereditary diseases. She had visited our hospital over 20 times and had been diagnosed with gastroenteritis. A physical examination revealed tenderness in the epigastric region and hyperactive bowel sounds. An abdominal ultrasound showed remarkable gastric and duodenal edema (Fig. 1).

The patient's white blood cell (WBC) count and platelet count were $23,200 / \mathrm{mm}^{3}$ and $434,000 / \mathrm{mm}^{3}$, respectively. Her red blood cell count and creatinine, blood urea nitrogen, glucose, lipid, and transaminase levels were normal. HAE was suspected on the basis of these findings. The complement studies revealed a markedly reduced $\mathrm{C} 4$ level of $1 \mathrm{mg} /$ $\mathrm{dL}$ and the C1-INH level was decreased to $5.53 \mathrm{mg} / \mathrm{dL}$ (normal $15-35 \mathrm{mg} / \mathrm{dL}$ ) with an activity level of $<25 \%$ (normal

${ }^{1}$ Emergency and Critical Care Center, Kishiwada Tokushukai Hospital, Japan and ${ }^{2}$ Department of Internal Medicine, Kyushu University Beppu Hospital, Japan

Received for publication December 10, 2015; Accepted for publication February 4, 2016

Correspondence to Dr. Hiromasa Yakushiji, amorihamorih1111@yahoo.co.jp 


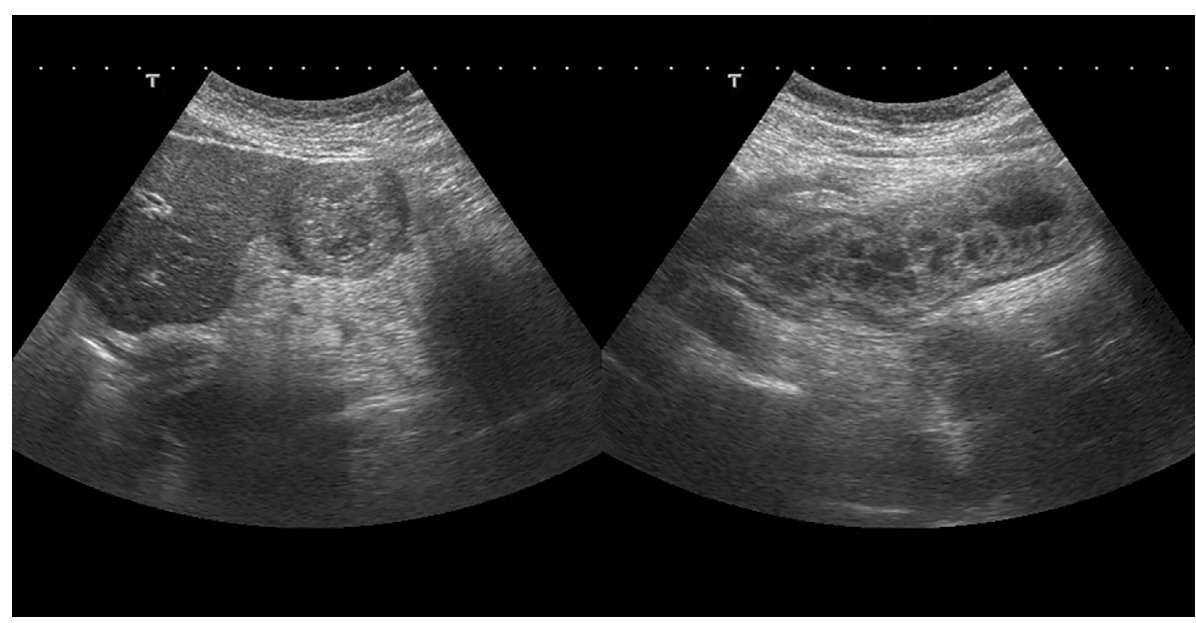

Figure 1. Abdominal ultrasound showing remarkable gastric and duodenal edema.

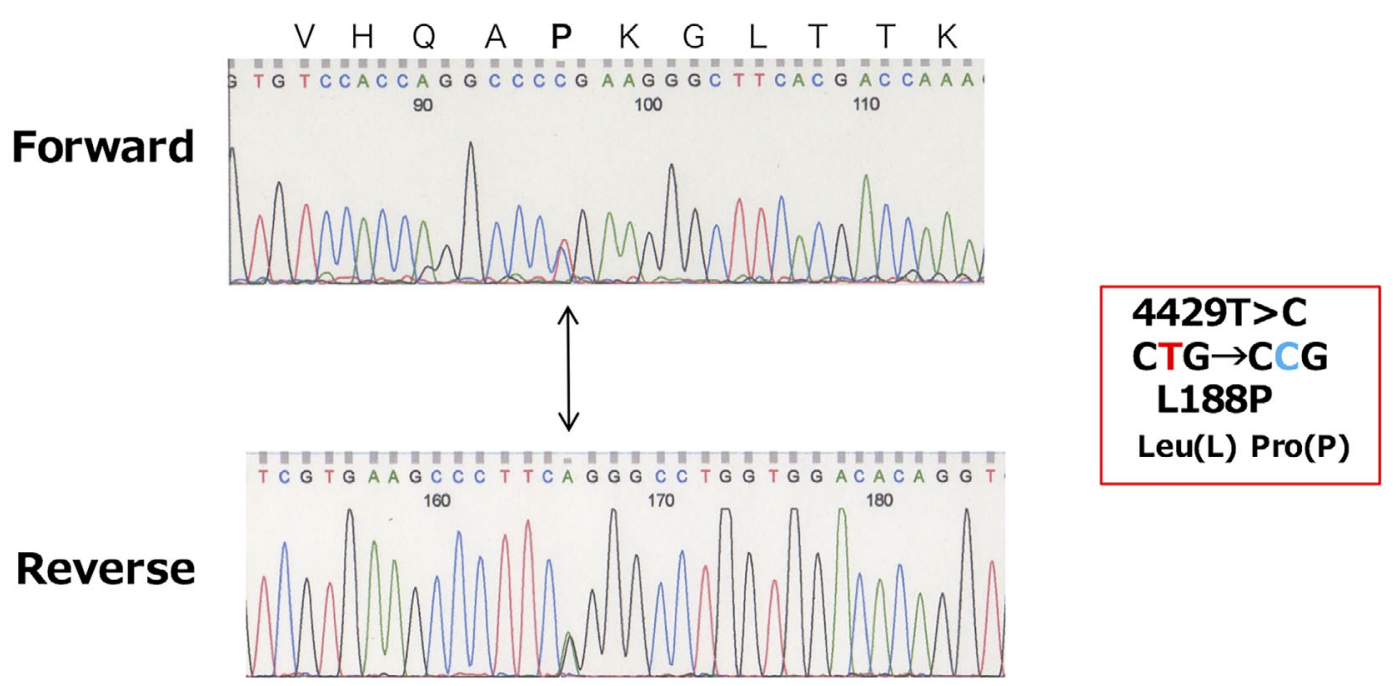

Figure 2. Direct DNA sequencing of the polymerase chain reaction (PCR) product of exon 4 from the patient identified a heterozygous, single-base substituteon ( $T$ to $C$ ) at nucleotide position 4429 (arrow). This mutation predicts substitution of Leu (CTG) at codon 188 by Pro (CCG).

$80-125 \%$ ). These laboratory data and the clinical features were compatible with a diagnosis of type I HAE; however, the patient had no family members with a history of similar episodes of recurrent edema or abdominal pain. To establish the diagnosis, we performed a DNA analysis of the C1-INH gene in the patient.

We asked the Center for Research, Education, and Treatment of Angioedema (CREATE) to perform a gene analysis. Venous blood samples were collected from the patient with informed consent. The patient was examined for C1-INH gene mutations by the direct sequencing of polymerase chain reaction (PCR) products. The screening of each exon for small mutations was performed using a single strand conformation polymorphism (SSCP) assay. The presence of large mutations presences was then investigated using an multiplex ligation-dependent probe amplification (MLPA) assay. A direct DNA sequencing analysis of the PCR products of the C1-INH gene revealed that the patient was heterozygous for a single base pair transposition of $\mathrm{T}$ to $\mathrm{C}$ at nucleotide 4429 in exon 4 (Fig. 2), which led to an amino acid substitution of Leu at codon 188 by Pro. No large mutations were detected in the MLPA analysis of the patient's DNA. The Leu to Pro substitution was considered to be a mutation because none of 50 healthy individuals carried this substitution (data not shown). This mutation has not previously been reported.

\section{Discussion}

In 1888, William Osler presented the first complete clinical description of HAE, which occurred over 5 generations in one affected family (6). Donaldson and Evans noted that a biochemical abnormality, the absence of $\mathrm{C} 1-\mathrm{INH}$, was responsible for HAE in 1963 (7). The gene encoding C1-INH has been revealed. It is located on chromosome 11q11q13.1, and consists of 8 exons, with most introns containing multiple Alu repeat sequences (8). An electronic database of the reported mutations is available (9). The most common 
defect is a single base pair mutation. It can occur throughout the gene and no correlation has been found between the genotype and the phenotype (10). Our patient had recurrent episodes of skin edema and abdominal pain, low $\mathrm{C} 4$ titers with decreased functional and antigenic levels of C1-INH. As this patient had no family history of angioedema, the differential diagnosis of sporadic HAE and acquired angioedema was necessary. A genetic analysis offers the clearest information for the diagnosis of such cases (11). The DNA analysis revealed that the patient had a novel mutation of $\mathrm{T}$ to $\mathrm{C}$ at nucleotide 4429 in exon 4 of the $\mathrm{C} 1-\mathrm{INH}$ gene, which was consistent with a diagnosis of sporadic HAE type I. The patient was therefore carrying a de novo mutation. Although we had hoped to examine her family for mutations of the C1-INH gene (to determine whether or not the present case was sporadic) her family members declined the examination due to their lack of symptoms. Since approximately $10 \%$ of individuals carrying the defective gene are asymptomatic, a DNA analysis of the patient's parents should be performed (12).

HAE can be diagnosed by the careful investigation of clinical features and laboratory findings. However, it is sometimes misdiagnosed or overlooked, as a shown by a review of the Japanese literature revealed that the mean interval between the onset of symptoms and the diagnosis of HAE was 19 years (13). The patient had episodic edema of the extremities and facial skin and recurrent gastrointestinal attacks that occurred in association with her menstrual period. Although these were typical symptoms of HAE, she had visited our hospital more than 20 times and had only been diagnosed with gastroenteritis. It is therefore of great importance to learn more about this disease.

We described a case of type I HAE with a novel mutation of $\mathrm{T}$ to $\mathrm{C}$ at nucleotide 4429 in exon 4 of the C1-INH gene. The patient had recurrent gastrointestinal attacks. HAE should be considered in the differential diagnosis of abdominal pain. When a clinician suspects C1-INH deficiency, even in patients with no family history, we recommend that, when possible, physicians investigate $\mathrm{C} 4, \mathrm{C} 1$ inhibitor function and $\mathrm{C} 1$ inhibitor antigenic protein.

The authors state that they have no Conflict of Interest (COI).

\section{References}

1. Bowen T, Cicardi M, Farkas H, et al. 2010 International consensus algorithm for the diagnosis, therapy and management of hereditary angioedema. Allergy Asthma Clin Immunol 6: 24, 2010.

2. Waytes AT, Rosen FS, Frank MM. Treatment of hereditary angioedema with a vapor-heated $\mathrm{C} 1$ inhibitor concentrate. N Engl J Med 334: 1630-1634, 1996

3. Tosi M. Molecular genetics of $\mathrm{C} 1$ inhibitor. Immunobiology 199: 358-365, 1998.

4. Zuraw BL, Herschbach J. Detection of $\mathrm{C} 1$ inhibitor mutations in patients with hereditary angioedema. J Allergy Clin Immunol 105: 541-546, 2000.

5. Pappalardo E, Cicardi M, Duponchel C, et al. Frequent de novo mutations and exon deletions in the Clinhibitor gene of patients with angioedema. J Allergy Clin Immunol 106: 1147-1154, 2000.

6. Osler W. Hereditary angioneurotic edema. Am J med Sci 95: 7, 1888.

7. Donaldson VH, Evans RR. A biochemical abnormality in herediatry angioneurotic edema: absence of serum inhibitor of C'1esterase. Am J Med 35: 37-44, 1963.

8. Carter PE, Duponchel C, Tosi M, Fothergill JE. Complete nucleotide sequence of the gene for human $\mathrm{C} 1$ inhibitor with an unusually high density of Alu elements. Eur J Biochem 197: 301-308, 1991.

9. Kalmár L, Hegedüs T, Farkas H, Nagy M, Tordai A. HAEdb: a novel interactive, locus-specific mutation database for the $\mathrm{C} 1$ inhibitor gene. Hum Mutat 25: 1-5, 2005.

10. Bygum A, Fagerberg CR, Ponard D, Monnier N, Lunardi J, Drouet C. Mutational spectrum and phenotypes in Danish families with hereditary angioedema because of $\mathrm{C} 1$ inhibitor deficiency. Allergy 66: 76-84, 2011.

11. Horiuchi T, Ohi H, Ohsawa I, et al. Guideline for hereditary angioedema (HAE) 2010 by the Japanese Association for Complement Research: secondary publication. Allergol Int 61: 559-562, 2012.

12. Roche O, Blanch A, Caballero $T$, Sastre N, Callejo D, López-Trascasa M. Hereditary angioedema due to $\mathrm{C} 1$ inhibitor deficiency: patient registry and approach to the prevalence in Spain. Ann Allergy Asthma Immunol 94: 498-503, 2005.

13. Yamamoto $T$, Horiuchi $T$, Miyahara $H$, et al. Hereditary angioedema in Japan: genetic analysis of 13 unrelated cases. Am J Med Sci 343: 210-214, 2012.

The Internal Medicine is an Open Access article distributed under the Creative Commons Attribution-NonCommercial-NoDerivatives 4.0 International License. To view the details of this license, please visit (https://creativecommons.org/licenses/ by-nc-nd/4.0/).

(C) 2016 The Japanese Society of Internal Medicine http://www.naika.or.jp/imonline/index.html 